\title{
RICHARD ROGERS E A TRANSIÇÃO DO HIGH-TECH PARA O ECO-TECH
}

\author{
Camila Le Bourlegat, Mariane Olivo, Korina Aparecida Teixeira Ferreira da Costa
}

Universidade do Oeste Paulista - UNOESTE, Curso de Arquitetura e Urbanismo, Presidente Prudente, SP. E-mail: korina.arq@gmail.com

\section{RESUMO}

A preocupação e necessidade por edificações mais sustentáveis nos últimos anos tem movido pesquisadores e cientistas a desenvolverem materiais que diminuam o impacto ambiental, com menos resíduos e poluentes e que não gerem tantos esforços energéticos, tornando-se mais facilmente degradáveis. Nessa linha de pensamento após a arquitetura modernista, novos conceitos de sustentabilidade na construção civilcomeçaram a surgir, entre eles o High Tech à sua evolução o Eco Tech. Neste artigo será tratado a arquitetura tardo modernista de Richard Rogers, conhecido mundialmente hoje pela tectônica utilizada que fundamenta-se não apenas no decorativismo, agregando a sustentabilidade, sem comprometer a inovação de suas obras.

Palavras-chave: Tardo modernista. High tech. Richard Rogers. Eco Tech. Sustentabilidade.

\section{RICHARD ROGERS AND TRANSITION OF HIGH-TECH FOR ECO-TECH}

\begin{abstract}
The concern and need with Sustainable Buildings More in the last year has moved researchers and scientists develop materials one what a reduce the environmental impact, with less waste and pollutants and what a not generate so many energetic efforts, making -If more easily degradable. I thought this line after modernist architecture, new concepts of sustainability in civil construction began to emerge, eels among the High Tech your evolution Eco Tech. This article will treaty architecture latemodernism Richard Rogers, known worldwide today for tectonic used what a based -If not just not decorativism, adding sustainability without compromising innovation your works.

Keywords: Latemodernism, High Tech. Richard Rogers. Eco Thec. Sustainability.
\end{abstract}


INTRODUÇÃO

Arquitetura ultra tecnicista ou tardo modernista é considerada uma extensão do pensamento moderno, a partir dos anos 60 e 70. Essa nova arquitetura retoma teorias como a "Estética da Máquina", baseada na tecnologia e no universalismo; os preceitos modernistas de LE CORBUSIER (Por uma Arquitetura, 1977), racionalidade e funcionalidade, planta livre, separação de estrutura e fechamento, e fachada livre. Além das retomadas modernistas, novas ideias e conceitos foram buscados pelos ultratecnicista, o pensamento utópico junto a tecnologia revoluciona a maneira de projetar desses novos arquitetos no período que se destacam.

Sua arquitetura é pragmática e tecnocrática na sua ideologia, levando a um extremo muitas ideias modernistas, de modo a ressuscitar e atualizar sua linguagem adormecida. A lógica moderna é exagerada, distorcida e transformada em algo belo pelo seu extremismo ou mordacidade. Também chamada de arquitetura HIGH TECH, sua beleza é resultado da perfeição técnica, ou seja, aqui, os meios da arquitetura passam a corresponder aos seus próprios fins. (CASTELNOU, 2015, p. sp. Apud RAJA 1986)

A nova arquitetura High Tech, baseado no teórico de CASTELNOU $(2015$, p. sp.) que se fundamenta nas pesquisas de Richard Meier e de todos os metabolistas e brutalistas, caracterizase como: Perfeccionismo - uso amaneirado e decorativo da tecnologia, com ênfase a proteção física, condicionamento térmico, isolamento acústico, iluminação natural e artificial; Universalismo - despreza a memória histórica, o contexto urbano, o entorno, cria soluções universais com o uso da tecnologia contemporânea e de sistemas inteligentes; Experimentalismo - através de atitudes pragmáticas e tecnocráticas, utiliza suas obras para experimentos; Abstracionismo -o abandono do inconsciente exposto, para o uso de formas e funções racionais.

Além das características descritas acima, este novo conceito representa um olhar mais crítico sobre questões sociais intrínsecas na arquitetura. A preocupação com ambientes mais sustentáveis é incorporado no ato projetual como uma atitude de projeto. Desta forma os arquitetos High Tech desenvolveram construções inteligentes, que buscam soluções para o desperdício energético, contendo sistema de termo acumulação e controle de brises, sistemas paisagístico interno e externo, e sistema de gerenciamento de infraestrutura. Segundo os dados,

$\mathrm{Na}$ arquitetura convencional cerca de $40 \%$ da energia elétrica consumida é destinada a iluminação e $20 \%$ destinada ao condicionamento do ar. Tais índices são elevados e encarecem os empreendimentos. (CASTELNOU, 2015, p. sp.)

Outro fator social que passou a ser percebido e utilizado como atitude de projeto pelos novos arquitetos, foi à preocupação com a análise do lugar e do entorno, sendo 
O ambiente construído que nos cerca é, em nossa opinião, a representação física de sua história e o modo pelo qual acumulou diferentes níveis de significados para compor a qualidade específica do local, não só pelo que aparenta ser em termos perceptuais, mas pelo que é em termos estruturais.(NESBITT, 1995, p. 565)

O projeto arquitetônico tem o dever de representar toda a memória do ambiente geográfico construído durante décadas ou até mesmo séculos, portante de histórias geradas pela cultura das diferentes gerações existente naquele ambiente geográfico, mesmo que sua forma seja modificada. Portanto, o lugar juntamente com seu entorno, ambiente geográfico, não é apenas o local em que a obra será inserida e sim o fator mais relevante para o início do projeto.

Com o tempo, no entanto, os princípios da arquitetura High Tech vão se intensificando, a preocupação com a sustentabilidade, com entorno e com a cultura e memória local torna-se cada vez mais influentes no ato projetual, assim a arquitetura passa por umprocesso evolutivo de sustentabilidade ${ }^{1}$, chegando aos anos iniciais do século XIX com a denominação de arquitetura Eco Tech.

Os arquitetos em destaque da arquitetura High Tech e Eco Tech são Norman Foster, Richard Rogers, Renzo Piano e Jean Nouvel.

Norman Foster (1935-) considerado um dos maiores representantes da arquitetura High Tech, o arquiteto inglês dedica-se ao projeto de grandes obras, intensificando a distinção entre estrutura e fechamento e explora todas as tecnologias disponíveis. Suas maiores obras foram: o Centro de Artes Plásticas Sainsbury, Univ. de EastAnglia (1976/78 Norwich), Hong Kong \& Shangai Bank (1979/85), Century Tower (1992,Tóquio). (BENEVOLO, A Arquitetura no Novo Milênio, 2007)

Renzo Piano (1937-) grande arquiteto italiano tardo modernista, busca a fundo explorar a tecnologia para a criação de edifícios mais sustentáveis. Sua identidade é determinada nas obras através da estética particular e do uso de estruturas inovadoras, sendo o aço principal elemento.A primeira obra de destaque do arquiteto foi Centre Pompidou em Paris, projetado em parceria com Richard Rogers,que culminou ao seu reconhecimento internacional; posteriormente outras importantes obras foram executadas, Laboratórios de Investigação PATS Centre (1973/82, Cambridge, Inglaterra) também em parceria com Richard Rogers, Aeroporto de Kansai (1988/94), Centro Cultural Jean-Marie Tijbaou (1991/98, Nova Caledônia). (BENEVOLO, A Arquitetura no Novo Milênio, 2007)

\footnotetext{
${ }^{1} \mathrm{~A}$ sustentabilidade deve ser entendida como um grande tema da cultura contemporânea, que afeta e transforma a teoria e a prática do desenho, reformulando-o frente à onipotência tecnológica e anti-sustentável da modernidade. (HICKEL, 2005, p. sp). 
Jean Nouvel (1945-) arquiteto francês que assim como os outros arquitetos tardo modernistas procura desfrutar de todos os potenciais tecnológicos disponíveis para criar edifícios inteligentes. Sua forma de desenvolver o conceito de projeto o diferenciava dos demais, antes de dar maior importância aos desenhos se preocupava em analisar e refletir sobre o programa que determina cada obra, sendo assim para ele "cada objeto pede uma arquitetura diferente". (BENEVOLO, 2007, p.188). Suas principais obras são, Institutdu Monde Arabe (1982/87, Paris), Dentsu Tower (1998/02, Tóquio), Torre Agbar (2004, Barcelona). (BENEVOLO, A Arquitetura no Novo Milênio, 2007).

\section{METODOLOGIA}

A metodologia basea-se numa investigação bibliográfica e se fundamentará numa abordagem qualitativa de pesquisa, utilizando-se como instrumento um levantamento bibliográfico e documental, que segundo Teixeira (2000, p. 137), busca a correlação entre a teoria e os dados, entre o contexto e a ação, a partir da compreensão dos fenômenos por meio de sua descrição e interpretação. Para o trabalho com o estudo do tipo de levantamento bibliográfico ocorrerá inicialmente um levantamento das principais produções no contexto nacional de estudos, considerando a peculiaridade do objeto de estudo.

Desse modo, percebe-se que a pesquisa qualitativa vale-se do método indutivo, segundo o qual parte da observação, da análise dos fatos particulares, dos registros para compor um quadro compreensivo para então constituir a generalização universal, ou seja, a teoria. O processo de indução vale-se do princípio do empirismo, no qual o conhecer é dar significado à realidade (KÖCHE, 1997, p. 62).

\section{RICHARD ROGERS}

Arquiteto inglês nasceu em Florença no ano de 1933,graduou na escola AA de Londres e na Universidade de Yale, New Haven, nos Estados Unidos. Finalizado os estudos formou o escritório EQUIPE 4, junto com sua esposa Sue e o casal Wendy e Norman Foster, que se dedicou desde o início ao uso da tecnologia de ponta. Porém, foi em parceria com Renzo Piano que Rogers projeta a grande obra que the trouxe reconhecimento internacional, O Centro Pompidou de Paris(1973/77), devido a exposição da estrutura do edifício de toda sua parte mecânica. Precursor da teoria funcionalista, Rogers utiliza a tecnologia e a expõe realçando seus materiais e sua beleza, sendo considerado gótico por buscar a originalidade da estrutura.O arquiteto ainda procede com 
alguns conceitos corbusianos, fachada livre, separação de estrutura e fechamento, desprovido de elementos comuns como portas e janelas. (CASTELNOU, 2015, p. sp.)

As páginas seguintes decorrerãosobre uma análise das principais obras do arquiteto em estudo Richard Rogers, compreendendo desde a elaboração do projeto, o estudo das tecnologias aplicadas, até sua execução. Baseado na definição de Kate Nesbittem o livro "Uma Nova Agenda para a Arquitetura" (1995) sobre a expressão tectônica que "indica não só a probidade material e estrutural de uma obra, mas também uma poética do construir subjacente à prática da arquitetura e das artes afins" (Nesbitt, 1995, p.560), será desenvolvida uma lincagem entre a definição da tectônica e onde ela se encontra em suas obras.

O NeoBankside compreende um conjunto de quatro edifícios composto por 217 unidades, residenciais, hexagonais que variam de 12 a 24 pavimentose um volume de escritórios com 6 andares. Segundo HELM(2013, p. sp),

Todos os edifícios do conjunto acatam as linhas do contexto imediato, o que é a de qualidade de todo o conjunto - ao contrário de partes individuais - e é o que dá força ao projeto. A concepção global remete à herança industrial da área durante os séculos 19 e 20, respondendo em uma linguagem contemporânea que reinterpreta a coloração e materiais da arquitetura característica.

Os pavilhões de aço e vidro remetem bem ao contexto da área em que está inserido; os vermelhos oxidados do Jardim de Inverno se harmonizam com o Tate Modern, um dos museus mais visitados do mundo, e a Ponte Blackfriars, próxima ao conjunto. Os painéis de madeira postos na parte externa dos edifícios atribuem uma sensação de aconchego queequilibra a sensação de rigidez e suavidade de lar. Baseado no teórico de $\operatorname{HELM}$ (2013, p. sp).

De acordo com o site oficial de RICHARD ROGERS (2015), o sistema estrutural foi pensado de forma que as estruturas externas sustentasse todo o carregamento do prédio, aliviando as áreas internas de elementos estruturais para que os espaços nos apartamentos fossem altamente flexíveis. Para que esse excesso de carga fosse possível utilizaram-se tirantes de aço queunido a cada três andares por nós fixados nas laterais transfere as cargas ao quadro estrutural.Segundo $\operatorname{HELM}(2013$, p. sp), “Os tirantes são localizados por fora do plano de revestimentos, permitindo que se expresse como um sistema legível e característico, conferindo ao conjunto uma linguagem carismática".

Os elevadores panorâmicos propiciam aos ocupantes dos edifícios vistas encantadoras de Londres e do rio Tâmisa, além da sensação vertical e dimensional do leste de cada edificação. Jardins de inverno criados nas extremidades norte e sul de cada bloco, com fechamento em vidro 
formam varandas. Suspenso da estrutura principal em uma plataforma leve possui grandes painéis deslizantes, que agem como adições ao espaço interior e terraços fechados.

Uma ampla área de convivência é criada ao nível do solo com bosques paisagísticos que delimitam duas claras vias públicas através do lote, ligando os jardins no exterior do Tate Modern até a rua Southwark. De acordo com $\operatorname{HELM}(2013$, p. sp), “A permeabilidade através do local foi um fator chave do projeto e a disposição imaginativa dos volumes fornece aos moradores generosas acomodações e máxima iluminação natural".

O escritório de paisagismo Gillespies desenvolveu diversos espaços ajardinados com ricos detalhes, ao redor dos caminhos que percorrem osedifícios. O ambiente final apresenta uma suavidade inspirado por vegetações nativas, criando uma harmonia com as linhas contemporâneas dos edifícios. Segundo HELM(2013), O NeoBankside encontra se no coração de Londres, assim suas áreas de convivência proporcionam aos moradores o desfrute do ambiente natural e ecológico criado no local que potencializa a criação de um microclima sendo o conjunto favorecido por este clima mais agradável. Além disso, "os jardins integram o NeoBankside ao Tate Modern e todo o seu entorno devido os caminhos planejados para que por ele os usuários tenham acesso à paisagem urbana ao redor" (HELM, 2013, p. sp).

O projeto paisagístico foi concedido para criar jardins restritos aos moradores dos edifícios de forma que os isolasse das vias públicas presente no local proporcionando um ambiente tranquilo para descontração dos moradores. Para que fosse possível ciar essa barreira entre o público e o privado, de acordo com HELM (2013, p. sp)“foi conseguida através do uso de bermas abundantemente plantadas, valas de seixo-alinhados, estacas de pedras alinhadas e calçadas estreitas que se combinam para criar um forte senso de identidade para o local". As bermas também criam uma harmonia com o Tate Modern integrando a paisagem do conjunto à do museu.

A tectônica de Richard Rogers no NeoBankside, está presente na utilização e exposição do material aço, dessa forma introduz uma ligação com a imagem industrial que pertence ao contexto histórico daquele local. O uso dos tirantes nas laterais externas dos prédios, além de favorecer o projeto na amplitude dos espaços internos, causa a sensação de um edifício resistente, seguro, ao mesmo tempo em que as pranchas de madeira e as membranas translúcidas suavizam essa visão industrial e proporciona sensação de aconchego e leveza a obra.A elaboração da disposição dos edifícios e o formato dos mesmos proporcionou a entrada de iluminação e ventilação natural por igual em todos os pavimentos. Outra característica tectônica que vale 
ressaltar foi a utilização da cor vermelho oxidado nos jardins de inverno que destaca o conjunto na paisagem do entorno.

A Torre BBVA Bancomer no México,é uma instituição financeira mexicana, fundada em 1932, como Banco de Comercio (Bancomer) segundo site do BBVA (2015). A sua sede será no "Passeio da Reforma" na Cidade do México.Esse banco serve mais de 11 milhões de clientes, tem 1.704 locais bancários e 4.286 caixas eletrônicos.

Em seu site (2015) diz que Richard em conjunto com o arquiteto mexicano Ricardo Legorreta ganhou um concurso para a concepção do novo edifício sede da BBVA Bancomer na Cidade do México em 2009. Tendo desenvolvido ao longo de muitos anos de amizade entre os arquitetos, a parceria entre eles resultou em um design inovador tanto para o edifício quanto a Cidade do México. As duas práticas têm diferentes linguagens arquitetônicas, mas valores comuns. Richard Rogers disse: "Ricardo usa muito forte cor, usamos mais aço e, juntos, têm-se centrado na criação de um edifício de carácter, com uma forte geometria vertical e ritmo".

Segundo RICHARD (2015) em seu site a torre de 50 andares irá fornecer cerca de 78.600 metros quadrados de espaço de escritório principal para o BBVA Bancomer e acomodará cerca de 4.500 funcionários.Quando for concluída ainda este ano, a torre BBVA Bancomer irá se tornar o edifício mais alto do México, com 235 metros de altura.

Ainda no site de Richard Rogers (2015) diz que o projeto evoluiu a partir de uma análise das diferentes orientações de cada fachada e baseia-se em tradições arquitetônicas mexicanas. A geometria do sombreamento exterior é utilizada para criar um projeto de estrutura que irá proteger cada fachada da luz solar e calor ao mesmo tempo otimizando a luz natural. Ela dá ao edifício uma textura que evoca telas de treliça tradicionais.

Segundo em seu site RICHARD (2015) a proposta baseou-se na geração de jardim aberto a fim de criar uma variedade de ambientes de trabalho, que são flexíveis e podem ser adaptados às novas formas de trabalho. Todas as áreas terão muita luz, excelentes vistas e acesso aos jardins. Estes jardins, permitiram que os espaço de trabalho poderão ser montados nas "aldeias verticais" e eles aumentarão a riqueza e variedade do ambiente de trabalho. As áreas comuns para os trabalhadores, como o refeitório (localizado em um terraço acima, com vista espetacular sobre o parque), e um auditório, são destinadas a incentivar o aumento da interação e criar um senso de comunidade, tanto entre os funcionários nos mesmos departamentos e entre os funcionários em diferentes divisões do Banco.

A nova torre irá proporcionar uma vista deslumbrante sobre o maior parque do México o Chapultepec e a Rua Paseo de la Reforma uma das mais importantes do México. 
A tectônica do projeto BBVA, está nas estruturas em aço, que não são apenas meros detalhes, mas sim toda a preocupação com insolação e ventilação do edifício; juntamente com o estudo do lugar para melhor atender a sociedade; assim como em seus jardins internos, as "aldeias verticais" faz com que sejam totalmente integrados e usáveis, pois não são apenas detalhes aleatórios, mas sim parte do projeto.

\section{CONSIDERAÇÕES FINAIS}

Pode-se observar a evolução da arquitetura de Richard Rogers desde a obra do Centro Jorge Pompidou, sua inserção na arquitetura mundial, até sua última obra ainda em andamento BBVA Bancomer no México, em que a construção do pensamento dele ao conceito Eco Tech ficou evidente que o arquiteto se inspira no condicionamento térmico, isolamento acústico, iluminação natural e artificial; junto com o perfeccionismo e uso da tectônica, não apenas como detalhe decorativismo, mas como algo que se adequa a sua arquitetura através da inovação, sustentabilidade e detalhes; assim o tornando-o um dos arquitetos mais citados da contemporaneidade com artigos, referências arquitetônicas, projetuais, realmente um grande exemplo a ser seguido e inspirado.

\section{REFERÊNCIAS}

BENEVOLO, Leonardo. A Arquitetura no Novo Milênio. São Paulo: Estação Liberdade,2007.

CASTELNOU, Antonio. Arquitetura Contemporânea. 2015.

HICKEL, Denis Kern. A (in) sustentabilidade na arquitetura. Disponível em $<$ http://www.vitruvius.com.br/revistas/read/arquitextos/06.064/426>. Acessado em março de 2015.

HELM. NEO Bankside / Rogers StirkHarbour + Partners. 2013. Disponível em < http://www.archdaily.com.br/br/01-93476/neo-bankside-rogers-stirk-harbour-mais-partners >. Acessado em março de 2015.

ROGERS. Rogers StirkHarbour + Partners. 2015. Disponível em < http://www.rshp.com/rshp_home>. Acessado em março de 2015.

LE CORBUSIER. Por uma Arquitetura. São Paulo: 2a ed. 1977.

NESBITT, Kate. Uma Nova Agenda para a Arquitetura. Cosac Naify, 1995.

KÖCHE, J. C. Fundamentos de metodologia científica: teoria da ciência e iniciação à pesquisa. 22. ed. São Paulo: Vozes, 2004.

TEIXEIRA, E. As três metodologias. 2a .ed. São Paulo: Vozes, 2000. 